\title{
CONVERGENCE OF REGIONAL AND STATE RATES OF GROWTH OF INCOME, EMPLOYMENT, AND POPULATION: 1969-2000
}

\author{
Edward Nissan*
}

\begin{abstract}
This study uses historic growth data for the periods 1969-1978 and 1979-1988 and projections for the period 1988-2000 for income, employment and population to address the issue of convergence or divergence. Regional trends are examined based upon the coefficient of variation and analysis of variance, while state trends are analyzed using regression methodology. The results indicate a general trend toward convergence of the growth rates during recent decades.
\end{abstract}

\section{INTRODUCTION}

Regions and states differ in such factors as the availability of natural resources, the distribution of people because of natural growth or migration, and historical evolution. Yet as Bradshaw (1988) has pointed out, in the latter part of this century, the United States has moved toward a convergence in values, tastes, and economies, creating a more homogeneous society. The influence of the federal government, the establishment of a national market, and the migration of people have played a large part in this transformation. The migration or movement of people, with the exception of retirees, is usually induced by the desire to seek better jobs or to alleviate unemployment, as was indicated by Herzog and Schlottmann (1984); people move out of areas with job shortages to areas where jobs are plentiful. In the process, as Levy (1988) has shown, regional income differences are reduced, as those who move from poor regions raise the average income of the sending regions and lower the income of the receiving regions.

Despite this move toward convergence, as Amos $(1983,1989)$ contends, state and regional income inequalities persist. He shows that though the variation of per capita income among states continued to decline between 1932 and 1978, a noticeable increase took place from 1978 to 1985 . The recent imbalance is in part the result of the initiation of major product innovations such as computer technology, which tend to favor some specific areas over others, thus stimulating growth in that particular region. An example is the special advantage the New England region had during the 1980 s because of the increase in demand for minicom-

\footnotetext{
*Professor of Economics and International Business, The University of Southern Mississippi. The author would like to thank anonymous referees and the editors of this joumal for helpful comments and suggestions on an earlier draft of this paper.
} 
puters, a product in which the region specializes. Garnick (1990) supports the view that regional differences in per capita income as a percent of the national average widened in the 1980 s in contrast to the experience of the previous five decades. He states that from 1929 to 1979, the per capita personal income in the low-income regions (Southeast, Southwest, Plains, and Rocky Mountain) increased from 64 percent of the national average to 90 percent. For the high-income regions (Mideast, Far West, New England, and Great Lakes), the reverse was true, with these regions witnessing a decline in income from 127 percent of the national average to 107 percent. This trend was reversed a bit during the period from 1979 to 1988 , when the income of the low-income regions was 88 percent of the national average as compared to 109 percent for the high-inome regions.

This article intends to complement the findings of these studies by looking not at regional per capita income inequalities, but at the inequalities of growth rates of various macroeconomic variables on regional and state bases. While growth depends mostly on the national economy, the experience for individual regions and states could be profoundly different. Therefore, the interest here is to deduce whether growth in recent years has become more equal because of the operation of market forces or less equal because of specific advantages that some regions or states possess. For this purpose, annual growth rate data by state and region for earnings, employment, total personal income, population, and per capita personal income for the periods 1969-1978 and 1979-1988 and projections for the period 1988-2000 are explored to investigate the question of convergence in regional and state economic trends. First, it compares regional annual growth rates of the five variables in the three periods, using coefficient of variation and analysis of variance. Second, it compares the variation on a state-by-state basis by means of simple linear regression.

\section{DATA AND VARIABLES}

Annual rates of growth data by state for 1969-1978 were obtained from the Bureau of Economic Analysis (BEA) publication (1980); the data for 1979-1988 and the projections for 1988-2000 were obtained from Johnson, Kort, and Friedenberg (1990), who state (on page 39) that extensive use was made of econometric modeling of the state economies, which allowed the consideration of complex economic and demographic interrelationships. They also state (on page 33) that these are baseline projections obtained by extending past economic relationships through 1988 and by assuming no major policy changes. According to BEA $(1974,26)$, examples of policy changes may include the establishment of 
new towns or new environmental regulations concemed with such issues as strip mining or pollution abatement.

Dougherty (1992) differentiates between ex post prediction from regression, in which case a dependent variable is predicted from future known independent variables, and forecasting, where prediction of a particular value of the dependent variable is made without knowing the actual values of independent variables. Projections, on the other hand, differ from forecasting, according to Rowley, Redman, and Angle $(1991,14)$, because the dependent variable is projected, provided specified assumptions hold true, while not assigning a probability to those assumptions that do hold true. Therefore, the projected states' growth rates are a description of the most likely pattern of growth or decline, depending on political and economic circumstances that are unknowable. Despite this limitation, they suggest the extent of future growth. Because national economic conditions in future years are assumed to be somewhat different from previous years, it is anticipated that different patterns of state and regional change will occur. This, of course, will depend on the factors that determine the national patterns and on the relative importance of these factors to particular states and regions in shaping their economies.

\section{VARIATION BY ECONOMIC REGIONAL AREAS}

The groupings of states into regions are based on the Bureau of Economic Analysis classification. Although the BEA excludes Alaska and Hawaii, in this paper these states are included in the Far West region. ${ }^{1}$ Such regional groupings provide numerical convenience in aggregating information into large units. Differences among states within regions, as well as differences between regions, can be detected by two simple methods: the coefficient of variation and the analysis of variance.

The coefficient of variation (CV) obtained by dividing the standard deviation "S" of a distribution by its mean $(\bar{X})$, unlike the variance, is independent of the mean, making it easy to compare the standard deviation of a variable with different means at different time periods. This aspect provides a control for the tendency of distributions with larger means to have larger standard deviations. By controlling the mean, the implication is that the larger the coefficient of variation, the more dispersion there is within the group or, in other words, the more the inequality among members of the group. In Table 1, the coefficient of variation CV $(S / \bar{X})$ is given for earnings, employment, total personal income, population, and per capita income for the three periods identified by the numbers " 1 " through " 3 ." 


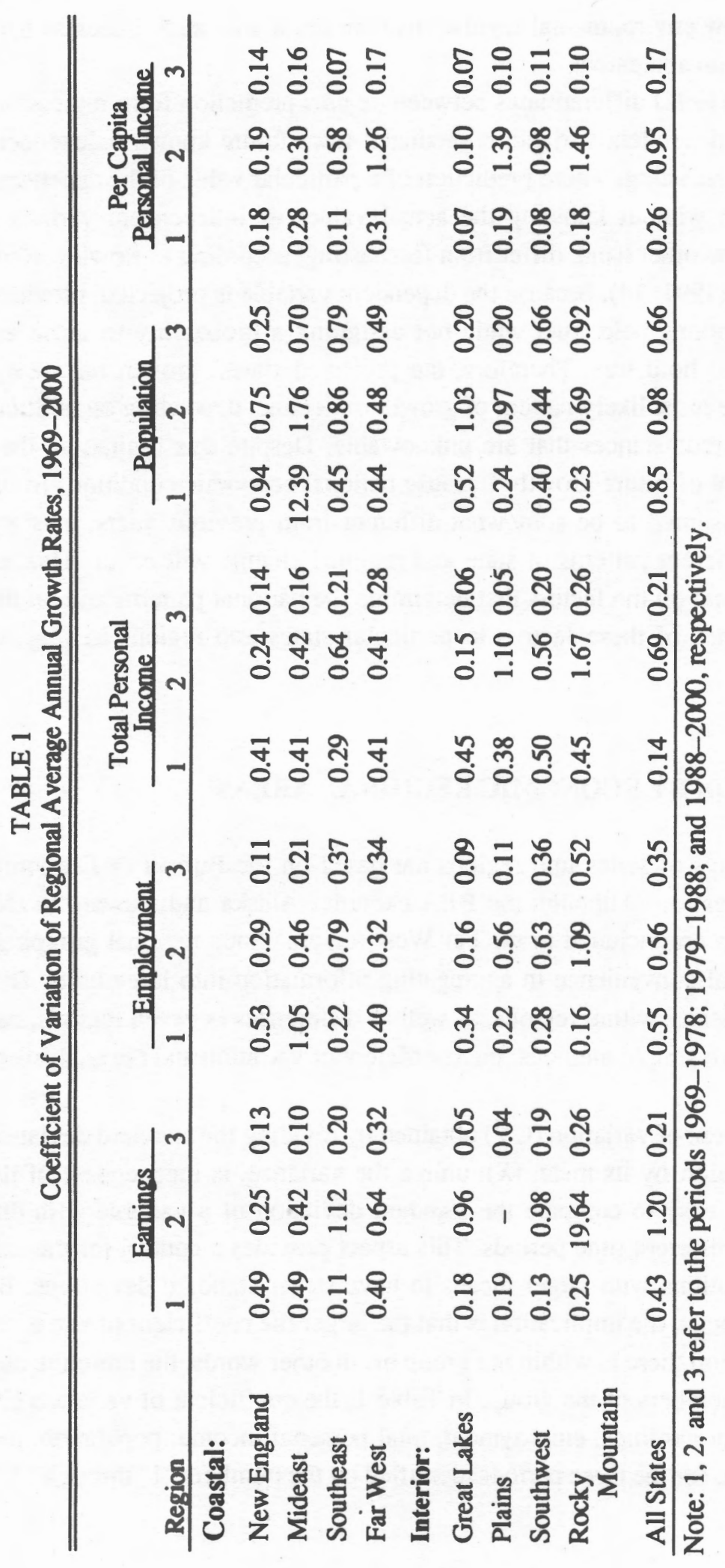


The coefficient of variation in the majority of cases for 1979-1988 (period 2) was larger than its counterpart in 1969-1978 (period 1), indicating an increase in inequality among the states within regions during period 2 as compared to period 1. This is also true for all the states given in the last row of Table 1. However, the coefficient of variation, with two exceptions, falls for all regions for every indicator in the projected period $1988-2000$ (period 3) as compared to 1979-1988 (period 2). The decline of the coefficient of variation in the projected period evidences a narrowing of the gap of the growth rates among the states within each region toward that region's average. However, in some instances, the regional average growth in the projected period is higher than in the former period. In other words, the dispersions were reduced despite the increases in their average levels.

Table 1 also shows a consistent pattem of change for some regions. For the New England, the Mideast, and, to a certain extent, the Far West regions, the coefficient of variation in a later period is less than or almost equal to a former period for all the variables, indicating a systematic decrease in inequality among the states within these coastal regions. On the other hand, the Southeast, Plains, Southwest, and Rocky Mountain regions (interior regions) changed direction, having consistently higher coefficients in period 2 (1979-1988) than in the former period.

To test the null hypothesis of equality of the growth rates across regions, the analysis of variance is performed for all three periods. If $\mathrm{F}$ is significantly large, it is of interest to determine how the regions differ in their growth rates. To find these differences, a multiple comparison procedure by the method of least-significant-difference is employed, as explained by Kleinbaum, Kupper, and Muller (1988, 361-372). The results are shown in Table 2.

The $F$ test for all the variables for the periods $1969-1978$ and $1979-1988$ strongly rejects the null hypothesis of equality of the growth rates. The p-values for the former period were all zero, while the p-values for the latter period ranged from a low of zero to a high of .02 , giving support to the alternative hypothesis. For the projected period 1988-2000, however, the p-values, with the exception of per capita personal income, were larger than their counterparts in the 1979-1988 period, giving stronger credibility to the null hypothesis of equality of the growth rates. These results indicate that regional growth rates for the variables under consideration tended to be more alike over time, a perception enforced by the $\mathrm{F}$ ratios (Table 2), which, with the exception of per capita personal income, consistently decreased. According to Yamane $(1966,627)$, the more the $F$ ratio exceeds unity, the greater the variation between the means, or, in other words, the larger the value of $F$, the less credible is the null hypothesis. For example, the $F$ ratio for earnings decreased from 11.72 in 1969-1978 to 4.85 in 1979-1988 and decreased 
TABLE 2

Multiple Comparisons of Regional Average Annual Growth Rates 1969-2000

\begin{tabular}{lcrr}
\hline \hline Variable & Comparisons & Fratio & p-value \\
\hline Earnings & & & \\
$1969-1978$ & {$[(2,1,5) ;(5,6) ;(6,3) ;(3,4,7) ;(4,7,8)]$} & 11.72 & .0000 \\
$1979-1988$ & {$[(8,6,5) ;(6,5,7) ;(5,7,3,4) ;(7,3,4,2) ;(4,2,1)]$} & 4.85 & .0004 \\
$1988-2000$ & {$[(5,2,1,6,3,8) ;(1,6,3,8,4) ;(3,8,4,7)]$} & 1.82 & .1088 \\
Employment & & & \\
$1969-1978$ & {$[(2,5,1) ;(5,1,6) ;(1,6,3) ;(4,7,8)]$} & 13.27 & .0000 \\
$1979-1988$ & {$[(5,6,8,3,2) ;(8,3,2,7) ;(3,2,7,4,1)]$} & 2.77 & .0189 \\
$1988-2000$ & {$[(6,5,3,1,2,8) ;(5,3,1,2,8,7) ;(7,4)]$} & 2.10 & .0644 \\
Total personal income & & & \\
$1969-1978$ & {$[(2,1,5) ;(1,5,6) ;(6,3) ;(3,4,7) ;(4,7,8)]$} & 13.75 & .0000 \\
$1979-1988$ & {$[(6,8,5) ;(5,3) ;(3,7,4,2,1)]$} & 4.47 & .0008 \\
$1988-2000$ & {$[(2,5,1,6,3,8) ;(6,3,8,4,7)]$} & 1.98 & .0805 \\
Population & & & \\
$1969-1978$ & {$[(2,5,6,1) ;(6,1,3) ;(7,8,4)]$} & 10.34 & .0000 \\
$1979-1988$ & {$[(5,6,2,1,3) ;(6,2,1,3,8) ;(7,4)]$} & 5.68 & .0001 \\
$1988-2000$ & {$[(5,6,3,2,8,1,7) ;(1,7,4)]$} & 2.32 & .0424 \\
Per capita personal income & & & \\
$1969-1978$ & {$[(1,2,5) ;(5,4) ;(4,6,3,7,8)]$} & 8.25 & .0000 \\
$1979-1988$ & {$[(8,6,4,7) ;(6,4,7,5) ;(5,3) ;(3,2) ;(2,1)]$} & 12.20 & .0000 \\
$1988-2000$ & {$[(1,4,2) ;(5,3) ;(3,7,8,6)]$} & 9.82 & .0000
\end{tabular}

Note: The numbers in the table refer to regions as follows: (1) New England;

(2) Mideast; (3) Southeast; (4) Far West; (5) Great Lakes; (6) Plains; (7) Southwest;

(8) Rocky Mountain. P-value is the smallest level at which the observed value of the test statistic $\mathrm{F}$ is significant.

further to 1.82 in $1988-2000$. Similar trends are observed for the other variables with the exception of per capita personal income.

The grouping of regions in ascending order of growth rates resulting from the multiple comparisons is shown in Table 2. Any two regions that are not included inside the same parentheses are considered to be distinguishably different. This procedure, again with the exception of per capita income growth rate, grouped more regions in common subsets in a later period than in the previous 
period. Therefore, with the exception of per capita personal income, regional growth rates appear to have a greater tendency toward convergence in a later period as compared to a preceding period. In simpler terms, the regional growth rate differences have become less noticeable over time, and subsets of regions in a later period include more members in common than in a former period. The groupings, furthermore, provide insights for the change in the rank order of regions for their rates of growth. For instance, projected growth rates of earnings are the highest for the Southwest and Far West regions, replacing New England and the Mideast regions in the previous period. In summary, even though differences in growth rates of some of the variables in the three periods oscillate among states within regions as observed from the coefficient of variation in Table 1, such differences between regions themselves tended to approach equality, as indicated by analysis of variance in Table 2 .

\section{VARIATION BY STATE}

The analysis so far was based on aggregation of states' data into regions. Aggregating on the basis of some preconceived notion of groups, however, ignores the wide differences among the individuals within each group. To address this, analysis of growth by states is undertaken, utilizing for this purpose a simple linear regression methodology. The model regresses the growth rate data of the five variables for the period 1979-1988 on the former period 1969-1987 and then regresses the projected data for the period 1988-2000 on the corresponding data of the former period 1979-1988. A justification for this specification is rooted in the theory of bivariate normal distribution. If it is assumed that the distribution of $\mathrm{Y}$ and $\mathrm{X}$ are two measurements on the same entity at two time periods, each separately normally distributed, then together, they are assumed to be jointly normally distributed, according to Dunn and Clark (1974). It follows, then, that the conditional mean is

$$
E[Y \mid X]=\mu_{Y}+\beta\left(X-\mu_{X}\right)
$$

where $E[Y \mid X]$ is the conditional expectation of $Y$ given $X$, and $\beta=\rho \sigma_{Y} / \sigma_{X}$. If the estimators $\bar{X}, \bar{Y}, s_{X}, S_{Y}, r$, and $b$ are substituted for the parameters $\mu_{X}, \mu_{Y}, \sigma_{X}, \sigma_{Y}$, $\rho$, and $\beta$ in the above expressions, the result is the linear regression

$$
Y^{\prime}=\bar{Y}+b(X-\bar{X})
$$

where $Y^{\prime}$ is an estimator of $E[Y \mid X]$. According to Hart and Pearce (1986), there is no scope for the relationship between $Y$ and $X$ to be nonlinear.

This model, suggested by Congdon and Shepherd (1988), is a regression written as 


$$
Y_{i}^{\prime}-\bar{Y}=b\left(X_{i}-\bar{X}\right)
$$

where $Y_{i}^{\prime}$ is the expectation from regression, $\bar{Y}$ is the average in a final period, $X_{i}$ is the observed, and $\bar{X}$ is the average in an original period. The magnitude and sign of the slope of the regression line $b$ is crucial. Using a terminology advanced by Coughlin and Mandelbaum $(1988,1989)$, though somewhat differently, an upward (downward) divergence takes place if $b>1$ and $X>\bar{X}(X<\bar{X})$ because deviations of $Y_{i}^{\prime}$ from their mean $\bar{Y}$ exceed the deviation of $X_{i}$ from their mean $\bar{X}$. Performance above (below) the mean in the initial period for a variable such as per capita income is enhanced further in the final period. There is a systematic tendency here for those states in the higher growth groups to receive an average proportionate increase higher than those in the lower groups. By a reversal of arguments, a downward (upward) divergence occurs when $b<-1$ and $X>\bar{X}(X \leq$ $\bar{X}$ ). When $0<b<1$, an upward (downward) convergence takes place if $X>\bar{X}$ $(X<\bar{X})$, and when $-1<\mathrm{b}<0$, a downward (upward) convergence occurs if $X>\bar{X}$ $(X<\bar{X})$.

By disaggregating the absolute difference

$$
Y_{i}-X_{i}=\left(Y_{i}^{\prime}-X_{i}\right)+\left(Y_{i}-Y_{i}^{\prime}\right),
$$

a structural change $\left(Y_{i}^{\prime}-X_{i}\right)$ and a deviational change $\left(Y_{i}-Y_{i}^{\prime}\right)$, which estimates the change in the relative position of a particular state, is obtained. The latter is a residualized difference that is uncorrelated with $X_{i}$ and thus, according to Zimmerman and Williams (1982), no spurious correlation exists between them. The expression $\left(Y_{i}^{\prime}-X_{i}\right)$ can be separated further by help from Equation (1) into:

$$
\begin{aligned}
Y_{i}^{\prime}-X_{i} & =\bar{Y}+b\left(X_{i}-\bar{X}\right)-X_{i} \\
& =(\bar{Y}-\bar{X})+(b-1)\left(X_{i}-\bar{X}\right) .
\end{aligned}
$$

This shows that the structural change is made up of a gap in average $(\bar{Y}-\bar{X})$, and a contribution from trend $(b-1)\left(X_{i}-\bar{X}\right)$.

Table 3 reports the means and variances for the three periods as well as the regression results placed under "I" and "II" for the five variables: eamings, employment, total personal income, population, and per capita personal income. The symbol "I" denotes the results obtained by regressing 1979-1988 states' growth rates on their counterparts in 1969-1978, while the symbol "II" denotes the results of regressing the projected period 1988-2000 rates on their counterparts in 1979-1988. The regressions are made for data in a final period $Y$ on corresponding data in a former period $X$. The fourth pair of columns presents the slopes of the regression, followed by their p-values in the fifth pair of columns. The last pair of columns gives $r$, the correlation coefficient. From Table 3, 
$-1<b<1$ for all the variables and are statistically significant ( $\mathrm{p}$-value close to zero) for all "II" regressions, indicating convergence in the projected period. However, under "I," a mixed picture emerges. The slopes of earnings, employment, total personal income, and population indicate convergence $(-1<b<1)$, and the slope of per capita income indicates divergence $(b<-1)$. All are significant with the exception of total personal income $(p$-value $=.65$ ). Therefore, the sole growth variable that showed divergence is per capita income, with a slope of $b=-1.11$ for the 1980s (Regression I), which is a result similar to that observed by Amos (1989); Garnick (1990); Coughlin and Mandelbaum (1988, 1989); and Rowley, Redman, and Angle (1991), who reported a rise in state per capita income inequality for this period. Since $b<-1$, the divergence is downward for states with higher than average growth in the 1970s $(X>\bar{X})$ and upward for states with lower growth rates $(X<\bar{X})$.

The correlation coefficients in Table 3 were tested for significance by

$$
t=(n-2)^{1 / 2} r /\left(1-r^{2}\right)^{1 / 2}
$$

where $n$ is the number of observations and $r$ is the sample correlation coefficient with 49 degrees of freedom. These were found, with one exception, to be significant. These correlation coefficients, as explained by Creedy (1985), depict mobility among the states and provide a measure of the degree of permanence of the leaders among them. They also show the extent to which states with slower growth can overtake the leaders. Since $r$ takes on values between -1 and 1 , the sign and the magnitude of $r$ are indicators of the movement of the states in the hierarchy of the growth rates. It is evident from Table 3 that permanence of leadership is strongest in the case of population. The $r$ values are positive and fairly high for both Regression I and Regression II, indicating that throughout the historic periods under consideration, as well as the projected period, those states with high population growth rates maintained their leadership. An opposite situation is witnessed for per capita income growth rates where $r$ is negative and fairly high, indicating a reversal in positions.

Table 4 lists the states with significant deviational change $\left(Y_{i}-Y_{i}^{\prime}\right)$ for all variables-positive when performance is better than expected, negative when performance is worse than expected-using the test statistic with $(n-2)$ degrees of freedom

$$
t=\left(Y_{i}-Y_{i}^{\prime}\right) /\left[s_{y}^{2}\left(1-r^{2}\right)\right]^{1 / 2}
$$

A one-sided test is chosen for superiority of performance $\left.\left[\left(Y_{i}-Y_{i}^{\prime}\right)>0\right)\right]$, or the reverse $\left.\left[\left(Y_{i}-Y_{i}^{\prime}\right)<0\right)\right]$. The one-sided $t$-value for 49 degrees of freedom is \pm 1.28 for a 10 percent significance. The states are listed for performance below expecta- 


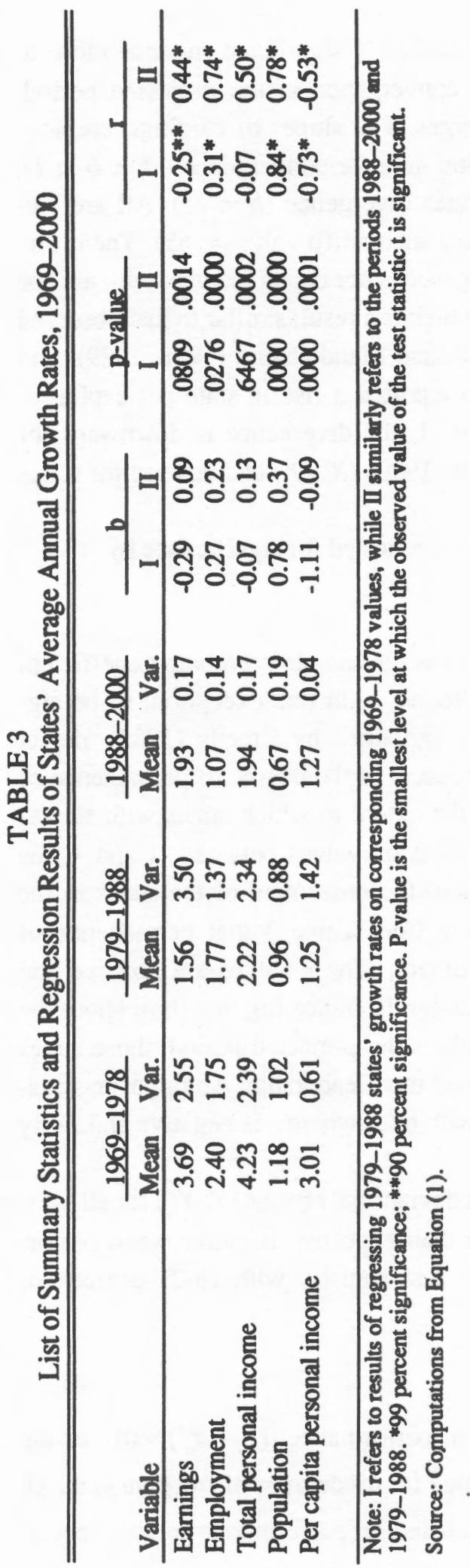


TABLE 4

List of States with Significant Deviational Change in Growth Rates

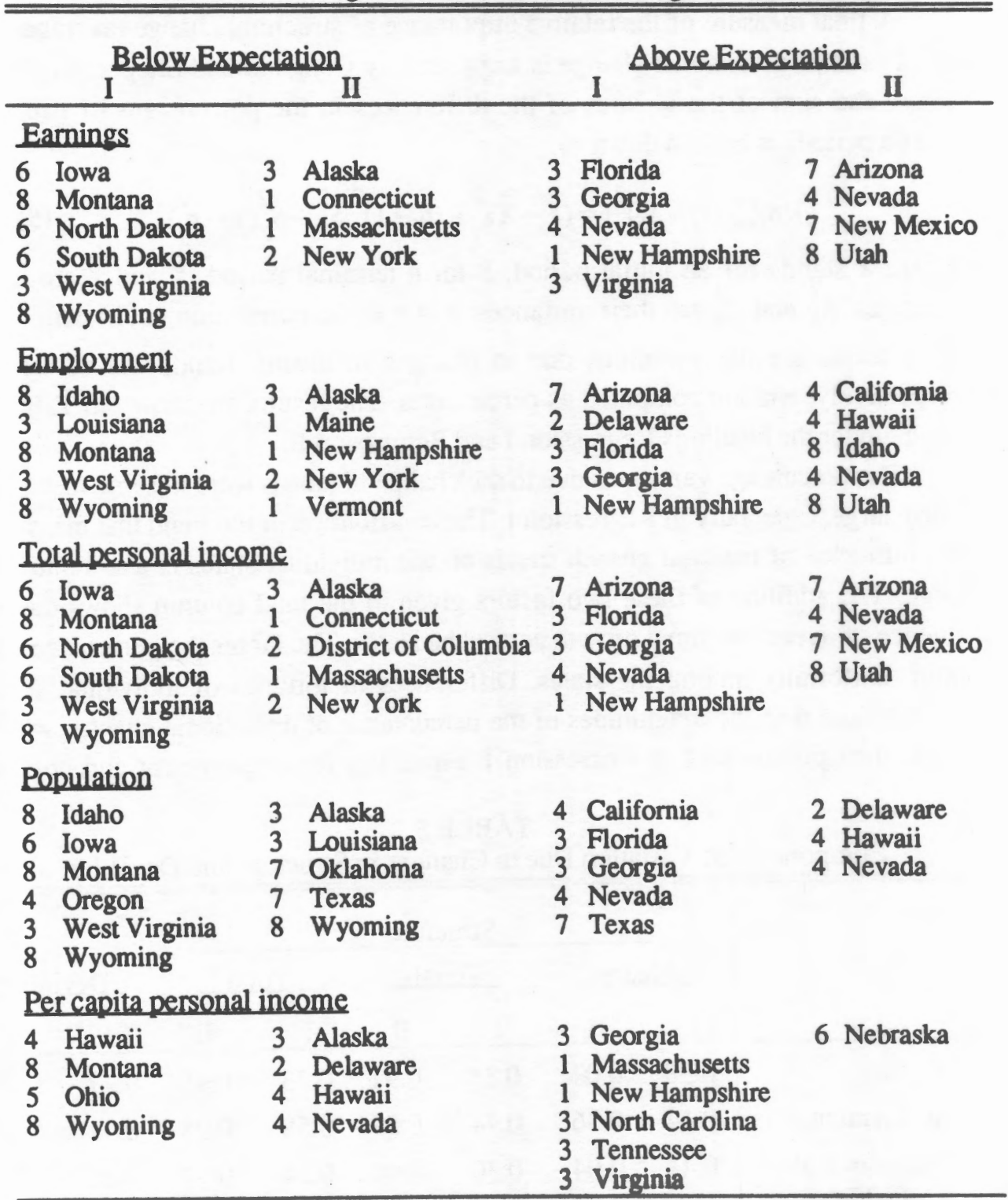

Note: I refers to results of regressing 1979-1988 states' growth rates on corresponding 1969-1978 values, while II similarly refers to the periods 1988-2000 and 1979-1988. Numbers in the table are for regional identification (see Endnotes). 
tion, and for performance above expectation. The symbols "I" and "II" refer to the periods of regression as outlined earlier.

A final measure of the relative importance of structural change (average and trend) and of deviational change is suggested by Congdon and Shepherd (1988), where the sum of the squares of the differences in the percentages of two observed periods is broken down as

$$
(1 / n)\left[\sum\left(Y_{i}-X_{i}\right)^{2}\right]=(\bar{Y}-\bar{X})^{2}+(b-1)^{2} s_{x}^{2}+S_{y}^{2}\left(1-r^{2}\right),
$$

where $X$ stands for an initial period, $Y$ for a terminal period, $\bar{X}$ and $\bar{Y}$ are their averages, $S_{X}^{2}$ and $S_{Y}^{2}$ are their variances, and $r$ is the correlation coefficient. The three terms are the variations due to changes in means, trend, and deviation, respectively, and are computed as percentages. The results are shown in Table 5, again under the headings Regression I and Regression II.

The percentage variations due to the change in means were in some instances fairly large, especially in Regression I. The contribution of the trend that measures the influence of national growth trends on the individual states is also relatively large. The addition of these two factors given in the total column shows the influence of overall national growth across the states. The larger the percentage, the more uniformity among the states. Differences in fortunes of individual states were reflected in the magnitudes of the percentages of deviational change, which were most pronounced in Regression I, especially for employment and popula-

\section{TABLE 5}

Components of Variation Due to Changes in Structure and Deviation

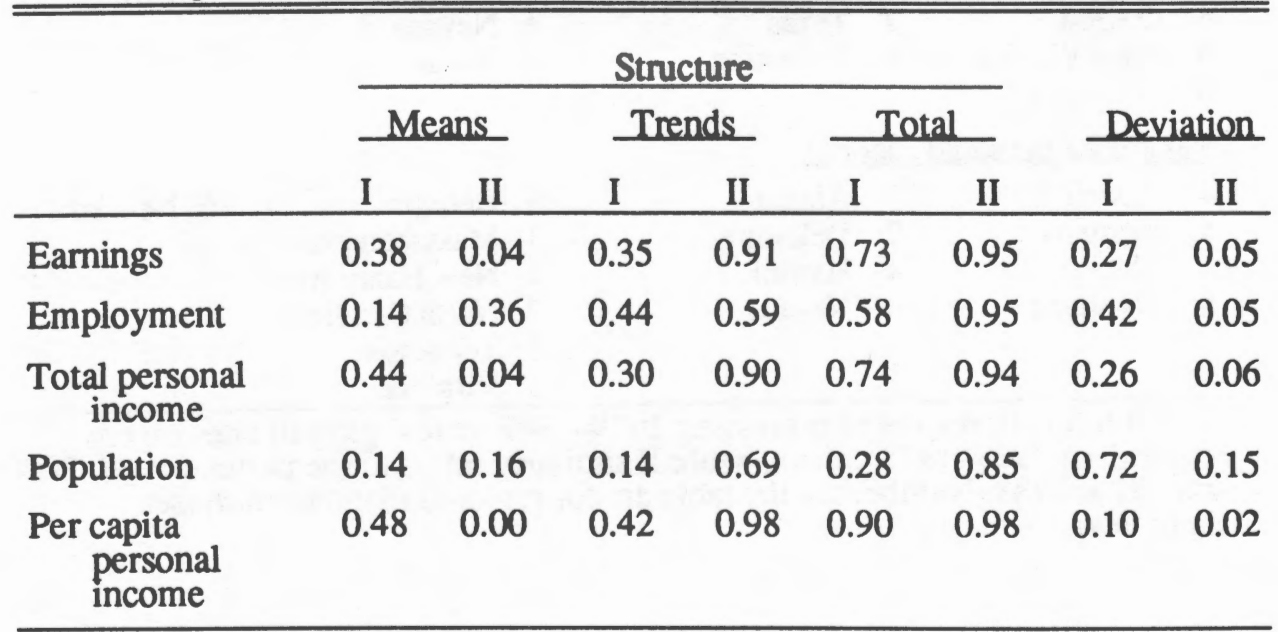

Note: I refers to results of regressing 1979-1988 states' growth rates on corresponding 1969-1978 values, while II similarly refers to the periods 1988-2000 and 1979-1988.

Source: Computations from Equation (5). 
tion. Table 4 is of help here for further insights. In employment, the states with significant deviational change below expectation were Idaho, Louisiana, Montana, West Virginia, and Wyoming. The states with a strong showing were Arizona, Delaware, Florida, Georgia, and New Hampshire. The remaining states maintained a uniformity close to the national experience. For population, the states that performed significantly below expectation in growth were Idaho, Iowa, Montana, Oregon, West Virginia, and Wyoming, while those that performed better than expected were California, Florida, Georgia, Nevada, and Texas. Again, the remaining states conformed with the national experience. For Regression II, the deviational change was approximately 5 percent for most variables, an indication of lessening in differences of future growth between the states.

\section{V.SUMMARY}

The focus of this paper is a comparison of regions' and states' performance for historical data for the periods 1969-1978 and 1979-1988 and a projected period 1988-2000. It looked for contrasts in annual growth rates of earnings, employment, total personal income, population, and per capita personal income to determine whether patterns of growth among regions and states are becoming more alike (convergence) or are increasingly differing (divergence). A general assessment is that during these decades, there is a general trend toward convergence for regions and states, a conclusion based partly on historical data and partly on projected data. In the absence of a reversal of national trends, and since the projected data are grounded on factors that determine states' economic conditions, the projections convey historical trends, thus making their use for analysis legitimate.

Many forces determine the growth or decline of the national economy, and the national economy in turn affects states and regions substantially, although perhaps unequally. Because the manufacturing sector has a leading role in providing employment, which directly and indirectly influences employment in the service sector, the continual shrinking of manufacturing narrows the differences in the economies of the states and regions, as Fothergill and Gudgin (1987) have maintained concerning Britain. In the absence of a strong nationwide rebirth in manufacturing, some states or regions may adopt policies to attract new investment, resulting in localized success, but these would not be enough to make them more prosperous or more economically vital than other states or regions, as was once true of the Mideast and the Great Lakes regions. 


\section{ENDNOTES}

1. According to the Bureau of Economic Analysis, regions of the United States include:

Coastal:

1. New England

Maine, New Hampshire, Vermont, Massachusetts, Connecticut, Rhode Island

2. Mideast

New York, Pennsylvania, New Jersey, Delaware, Maryland,

District of Columbia

3. Southeast

Virginia, West Virginia, North Carolina, South Carolina,

Georgia, Florida, Kentucky, Tennessee, Alabama, Mississippi,

Arkansas, Louisiana

4. Far West

Nevada, California, Oregon, Washington

\section{Interior:}

5. Great Lakes

Ohio, Michigan, Indiana, Wisconsin, Illinois

6. Plains

Minnesota, Iowa, Missouri, North Dakota, South Dakota,

Nebraska, Kansas

7. Southwest

Oklahoma, Texas, Arizona, New Mexico

8. Rocky Mountain

Colorado, Wyoming, Montana, Idaho, Utah

Not Classified:

Alaska, Hawaii

\section{REFERENCES}

Amos, Orley M., Jr. "The Sensitivity of Regional Income Variation to Cyclical Economic Fluctuations." The Review of Regional Studies 13 (1983): 4-11. "An Inquiry into the Causes of Increasing Regional Income Inequality in the United States." The Review of Regional Studies 19 (1989): 1-12.

Bradshaw, Michael. Regions and Regionalism in the United States. London: Macmillan Education, 1988. 
Bureau of Economic Analysis. "Regional and State Projections of Income, Employment, and Population to the Year 2000." Survey of Current Business 60 (November 1980): 44-71.

. Survey of Current Business. "State Projections of Income, Employment, and Population to 1990." 54 (April 1974): 21-45.

Congdon, Peter, and John Shepherd. "Components of Social Change in Urban Areas." Urban Studies 25 (June 1988): 173-189.

Coughlin, Cletus C., and Thomas B. Mandelbaum. "Why Have State Per Capita Incomes Diverged Recently?" Review of the Federal Reserve Bank of St. Louis 70 (September/October 1988): 24-36.

"Have Federal Spending and Taxation Contributed to the Divergence of State Per Capita Incomes in the 1980s?" Review of the Federal Reserve Bank of St. Louis 71 (July/August 1989): 29-42.

Creedy, John. Dynamics of Income Distribution. Oxford, England: Basil Blackwell, 1985.

Dougherty, Christopher. Introduction to Econometrics. New York: Oxford University Press, 1992.

Dunn, Olive Jean, and Virginia A. Clark. Applied Statistics: Analysis of Variance and Regression. New York: John Wiley \& Sons, 1974.

Fothergill, Stephen, and Graham Gudgin. Unequal Growth: Urban and Regional Employment Change in the U.K. Great Britain: Gower Publishing Company Limited, 1987.

Garnick, Daniel H. "Accounting for Regional Differences in Per Capita Personal Income Growth." Survey of Current Business 70 (January 1990): 29-40.

Hart, Peter E., and Robert D. Pearce. "Growth Patterns of the World's Largest Firms, 1962-1982." Review of World Economics 122 (1986): 65-79.

Herzog, Henry W., Jr., and Alan M. Schlottmann. "Labor Force Mobility in the United States: Migration, Unemployment, and Remigration." International Regional Science Review 9 (September 1984): 43-58.

Johnson, Kenneth P., John R. Kort, and Howard L. Friedenberg. "Regional and State Projections of Income, Employment, and Population to the Year 2000." Survey of Current Business 70 (May 1990): 33-54.

Kleinbaum, David G., Lawrence L. Kupper, and Keith E. Muller. Applied Regression Analysis and Other Multivariable Methods. Boston: PWS-Kent Publishing Company, 1988.

Levy, Frank. Dollars and Dreams: The Changing American Income Distribution.

New York: W.W. Norton \& Company, 1988.

Rowley, Thomas D., John M. Redman, and John Angle. The Rapid Rise in State Per Capita Income Inequality in the 1980's. Washington, D.C.: United States Department of Agriculture, Data Services Center, January 1991. 
Zimmerman, Donald W., and Richard H. Williams. "The Relative Error Magnitude of Three Measures of Change." Psychometrika 47 (1982): 141-147.

Yamane, Taro. Statistics, An Introductory Analysis. New York: Harper \& Row, 1966. 